A. I. KOSTYUKOV ${ }^{1,2}$

\title{
THEORETICAL ANALYSIS OF THE FORCE AND POSITION SYNERGIES IN TWO-JOINT MOVEMENTS
}

\author{
Received June 6, 2015
}

A theoretical approach is proposed to define the force and position singular points (FSPs and PSPs) in the circular, ellipsoidal, and linear planar two-joint movements produced under steady loadings directed along the movement traces. The FSPs coincide with changes in the direction of the force moments acting around the joints; the PSPs show the locations of the extrema at the joint angle trajectories. The force synergy (defined by the location of FSPs) provides a strong influence on the activation synergy; the latter is largely described by correlations between the activities recorded from the muscles participating in the movement. The position synergy (defined by the location of PSPs) is responsible for a hysteresis-related modulation of the activation synergy. Geometrical procedures are proposed to define positions of the FSPs and PSPs along various movement traces; this can provide a general description of the force and position synergies for the movements. The force synergies in the circular movements cover four sectors with diverse loading combinations of the flexor and extensor muscles belonging to different joints. The variability of the synergy effects for changes in the size and position of the circular trajectories is analyzed; the synergy patterns are also considered for ellipsoidal and linear movement traces. A Force Feedback Control Hypothesis is proposed; it allows one to explain the decrease in the number of controlled variables during real multi-joint movements.

Keywords: motor control, two-joint movements, muscle synergy, central commands, electromyogram.

\section{INTRODUCTION}

Three interdependent types of muscle synergies are usually considered when describing human movements. Both anatomical and neural factors are combined in coordinated joint movements, thus participating in various forms of the kinematic synergy that is displayed in simultaneous covariations during independent changes of the joint angles [1] and in various tasks of manual exploration [2]. The kinetic synergy, described usually by covariation of the forces (torques), has also been observed during grasping movements [1], in forced interaction of various fingers [3, 4], or during handwriting [5]. The muscle synergy, based on spatial and temporal coordination of multiple muscle activities, has been observed during

\footnotetext{
${ }^{1}$ University of Physical Education and Sport, Gdansk, Poland.

${ }^{2}$ Department of Movement Physiology, Bogomolets Institute of Physiology, National Academy of Sciences, Kyiv, Ukraine.

Correspondence should be addressed to A. I. Kostyukov

(e-mail: kostyuko@biph.kiev.ua).
}

static hand efforts [6] or in active force interactions of muscles of the digits $[7,8]$.

The anatomy of the human limbs usually does not allow experimenters to control all essential parameters defining the synergy effects; at least partly, this is related to practical impossibility of EMG recording from deeply located muscles. As a result, not all fundamental synergies can be identified experimentally in multi-joint movements of the limbs. In previous experimental studies of our group [9-11], we proposed an approach allowing one to analyze quantitatively the simplest form of the synergy effects in circular movements of the subject's right arm. The obtained results were used to find the functional relationships between basic mechanical parameters of two-joint movements and the related central commands. In order to determine inter-joint muscle interactions for these movements, we proposed a simplified classification of the synergy effects [11]; the same classification is used in the present study. In accordance with definitions accepted in the above study, we will further use the terms of position, force, and activation synergies, 
which are based on temporal changes in the following parameters, correspondingly: (i) joint angles, (ii) force moments at the joints, and (iii) activities of the muscles participating in a given movement. The terms force and position singular points, FSPs and PSPs, respectively, have also been introduced.

As was shown in [11], waveforms of the averaged EMG activities of the elbow and shoulder muscles are closely related to the correspondent sectors of the movement trajectories between neighboring FSPs, in which the force moments acting around the correspondent joints change their directions. Waves of the activity in these sectors are alternated in flexors and extensors; the activation patterns are reversed with changes in the loading direction. On the other hand, the EMG intensities are also dependent on the movement direction; such hysteresis-related effects are defined by sets of the PSPs (i.e., positions of the extrema at the joint angle traces).

The locations of the FSPs and PSPs were defined in [11] by computation of the time courses of the force moments and joint angles. At present, graphical methods begin to be widely used for the analysis of the synergy effects (see, e.g., [12]). In this study, we propose a graphical method for a theoretical definition of the force and position synergies for planar two-joint arm movements. In accordance with the methods described in [11], the axis of the proximal joint in our model is assumed to be in a fixed position, while the distal end of the other limb segment moves with a small constant velocity along the circular trajectory; the movements are produced under the action of constant loadings directed tangentially with respect to the trajectory. Afterwards, we extrapolated this consideration on the ellipsoidal and linear movement traces.

Hypothesis. Central commands to the muscles in two-joint movements and the related synergy effects are largely dependent on the relative positions of the FSPs belonging to different joints; muscle hysteresis participates in modulation of the commands in accordance with the location of the PSPs. An assumption has been put forward that, in order to decrease the number of the controlled variables in multi-joint movements, the CNS may use the force feedback channels from the antagonist muscles of different joints (a Force Feedback Control Hypothesis).

\section{RESULTS}

Curvilinear System of Coordinates. The present model is based on the two-joint planar upper limb movements produced under conditions of the fixed positions of the trunk and shoulder joint (see Methods in [11]). Naturally, the proposed consideration may be applied to the movements of the lower limbs, wich are realized, in particular, during a bicycle ride. The test movements, according to natural positioning patterns of the limb segments, can be analyzed within the framework of the curvilinear coordinate system shown schematically in Fig. 1. Four parameters, $R_{s}$, $\mathrm{R}_{\mathrm{e}}, \alpha$, and $\beta$, completely define the "hand" position

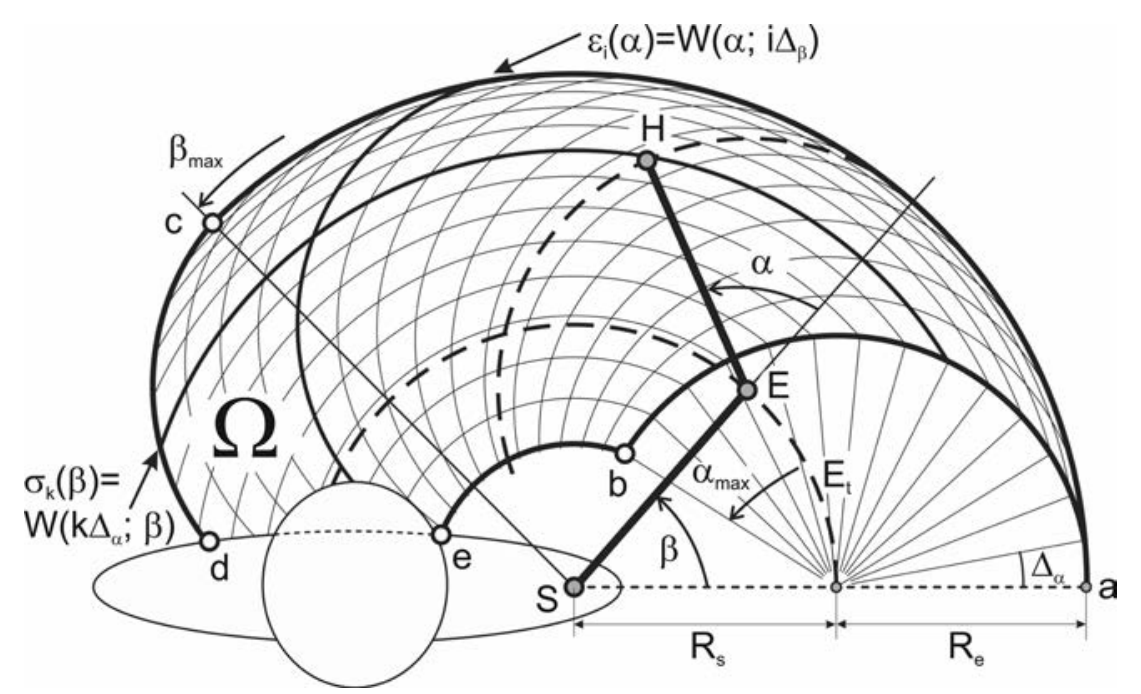

F i g. 1. Operational space of two-joint planar movements and definition of the curvilinear coordinate system. Parameters: $\alpha$ and $\beta$ ) elbow and shoulder joint angles changing within the following ranges: $\alpha_{\max } \leq \alpha \leq 0 ; \beta_{\max } \leq \beta \leq 0 ; \mathrm{R}_{\mathrm{s}}$ and $\mathrm{R}_{\mathrm{e}}$ ) lengths of the arm segments; $S$ and $E$ ) positions of the axes of the shoulder and elbow joints; $H$ ) "hand" position, i.e., position of the distal end of the second (distal) arm segment that can be called provisionally the "forearm"; $\varepsilon_{\mathrm{i}}(\alpha)$ and $\left.\sigma_{\mathrm{k}}(\beta)\right)$ basic elements of the curvilinear coordinate system (isolated movement traces in one of the joints when another joint is fixed). The curve a-b-e$\mathrm{d}-\mathrm{c}-\mathrm{a}$ indicates the boundary of the operational space $\Omega$.

Р и с. 1. Операційний простір двосуглобових рухів у площині та визначення криволінійної системи координат. 
(point $\mathrm{H}$ ) within the operational space $\Omega$. The first two of them, the shoulder and forearm lengths, $R_{s}$ and $R_{e}$, are characterized by fixed values for a given subject, whereas the two other parameters, namely angles $\alpha$ and $\beta$ (in the elbow and shoulder joints), change as independent coordinates within the ranges $0 \leq \alpha<\alpha_{\max }$ and $0 \leq \beta<\beta_{\max }$. Any target point within the operational space $\Omega$ can be presented as a function of the two variables, $\mathrm{W}(\alpha, \beta)$, which is based on simple trigonometric relationships (for details see [11]). Boundaries of the operational space $\Omega$ are as follows: $\mathrm{W}(0, \beta)(\operatorname{arc} a c$ in Fig. 1$) ; \mathrm{W}\left(\alpha, \beta_{\max }\right)(\operatorname{arc} c d) ; \mathrm{W}(\alpha, 0)$ $(\operatorname{arc} a b) ; \mathrm{W}\left(\alpha_{\max }, \beta\right)$ (arc be). Additionally, the curve $d e$ is defined by a natural trunk border of the subject.
Finally, the curvilinear coordinate system may be presented graphically by two sets of the intersected arc lines, $\varepsilon_{\mathrm{i}}(\alpha)=\mathrm{W}\left(\alpha ; \mathrm{i} \Delta_{\beta}\right)$ and $\sigma_{\mathrm{k}}(\beta)=\mathrm{W}\left(\mathrm{k} \Delta_{\alpha} ; \beta\right)$, where $\Delta_{\beta}$ and $\Delta_{\alpha}$ define the extent of discretization of the coordinates (Fig. 1). In the former case, arcs of radius $\mathrm{R}_{\mathrm{e}}$ are distributed with a constant density; in the latter one, arcs of the concentric circles with center $\mathrm{S}$ show an increased density with a shift toward the outer boundary of the operational space.

Force Singular Points Related to the Elbow Joint. A scheme of the hypothetical test movements is presented in Fig. 2A. During the test, the subject was asked to produce a slow circular-form steady movement; the movement trajectory is shown in
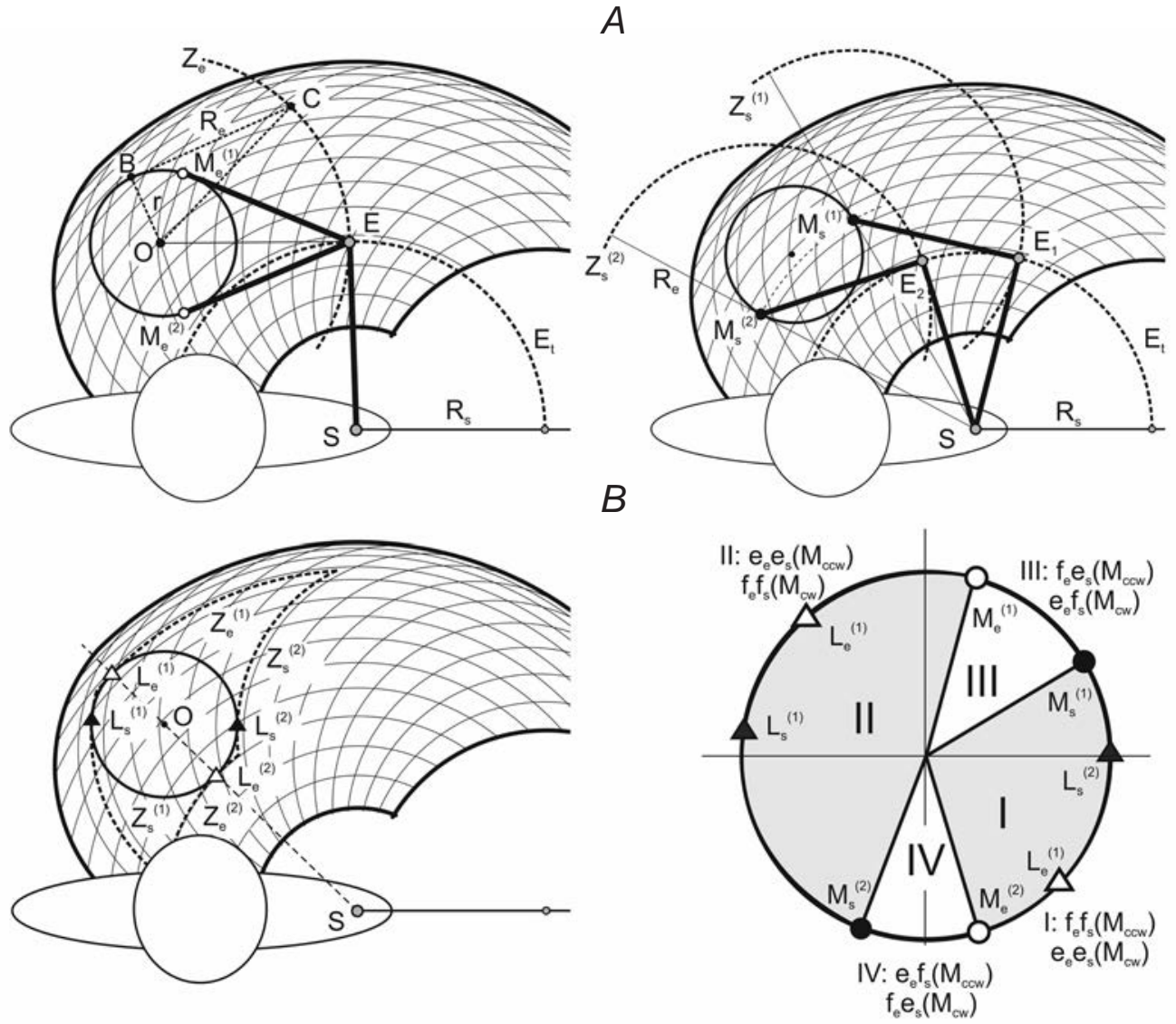

F i g. 2. Definition of the force and position singular points (FSPs and PSPs) and synergy sectors during circular movements of the hand. A) Definition of the FSPs at the elbow joint; $M_{e}^{(1,2)} ; Z_{e}$ ) virtual trajectory of the elbow joint positions at a zero moment; $E_{t}$ ) trajectory of possible spatial shifts of the elbow joint; E) elbow location defined by crossing of the $Z_{e}$ and $E_{t}$ curves. B) Definition of the FSPs at the shoulder joint; $\mathrm{M}_{\mathrm{s}}^{(1,2)}$; auxiliary circles $\mathrm{Z}_{\mathrm{s}}^{(1,2)}$ have the centers in $\mathrm{M}_{\mathrm{s}}^{(1,2)}$ and radii $\mathrm{R}_{\mathrm{e}} ; \mathrm{E}_{1}$ and $\mathrm{E}_{2}$ ) elbow locations defined by crossing the $\mathrm{Z}_{\mathrm{e}}$ ${ }^{(1,2)}$ and $\mathrm{E}_{\mathrm{t}}$ curves. C) Elbow PSP, $\mathrm{L}_{\mathrm{e}}^{(1,2)}$ (open triangles), and shoulder PSP, $\mathrm{L}_{\mathrm{s}}^{(1,2)}$ (closed triangles), coinciding with the extremal positions of the circle in the curvilinear coordinate system; the auxiliary curves are $\mathrm{Z}_{\mathrm{e}}^{(1,2)}$ and $\mathrm{Z}_{\mathrm{s}}^{(1,2)}$ (dashed lines). D) Location of the FSPs and PSPs, and of the force synergy sectors I-IV, in which the correspondent combinations of the elbow and shoulder muscles obtain the external loading; symbols $\mathrm{f}$ and e designate flexor and extensor muscles; subscripts e and s show muscles belonging to the elbow and shoulder joints; $\mathrm{M}_{\mathrm{cw}}$ and $\mathrm{M}_{\mathrm{ccw}}$ are clockwise and counterclockwise directions of the external loading.

Р и с. 2. Визначення силових та позиційних сингулярних точок і секторів синергії у кругових рухах руки. 
Fig. $2 \mathrm{~A}$ by the circle with center $\mathrm{O}$ and radius $\mathrm{r}$. It is assumed that test movements are produced under the action of a constant external loading applied tangentially with respect to the movement trace in clockwise or counterclockwise directions.

The force moment acting around the elbow joint attains a zero value when the external force vector is going via the joint axis; therefore, in this case the "forearm" should be directed tangentially with respect to the movement trace. The term "forearm" is used here in quotation marks to designate the distance from the elbow joint axis to the point of the external force application; it is assumed that the subject's wrist is rigidly fixed along the line connecting centers of the wrist and elbow joints. The scheme in Fig. 2A demonstrates the geometrical procedure used to determine the FSPs at the circular movement trajectories. The equilibrium elbow joint position $\mathrm{E}$ is defined as the point of intersection of the auxiliary curve $Z_{e}$ and elbow trace $E_{t}$. The arc $Z_{e}$ is the part of the circle passing via ends of the "forearm" length segments placed tangentially with respect to the movement trajectory. The point $\mathrm{E}$ is connected with two different "forearm" positions corresponding to two FSPs $\left(\mathrm{M}_{\mathrm{e}}^{(1,2)}\right)$ in the movement trajectory. These FSPs divide the circle into two unequal segments differing from each other by the sign of the force moments applied to the elbow joint muscles. For the clockwise directions of both external loading and movement, the force action at the elbow joint is changed from extension to flexion during transition via point $\mathrm{M}_{\mathrm{e}}{ }^{(1)} ; \mathrm{a}$ further passing via point $\mathrm{M}_{\mathrm{e}}^{(2)}$ evokes a reverse action. Therefore, for the clockwise-directed loadings, the elbow joint will undergo the action of extending/ flexing forces during the movement along the longer/ shorter segments of the circle divided by points $M_{e}^{(1,2)}$; for the counterclockwise loadings, the force moments will change in the opposite direction.

Force Singular Points Related to the Shoulder Joint. The force moment acting at the shoulder joint attains a zero value when the vector of the external force is going via the joint axis; therefore, the FPSs are shown by points of touching of the movement circle by two tangent lines $Z_{s}^{(1,2)}$ passing via the joint axis (Fig. 2B). The shoulder FPSs are placed symmetrically with respect to the line connecting the center of the movement circle and the joint axis. The definition of the elbow joint positions $E_{1}$ and $E_{2}$ for the given FPSs can be derived as points of intersection of the elbow trace $E_{t}$ with the circles of the radius $R_{e}$ that are centered in $M_{s}^{(1,2)}$. Similarly with the elbow joint, the shoulder FPSs define changes in the force moments during the movement. When both external force and movement have the clockwise direction, the force moment changes its action from extension to flexion at point $\mathrm{M}_{\mathrm{s}}{ }^{(1)}$; further movement via point $\mathrm{M}_{\mathrm{s}}{ }^{(2)}$ will produce an opposite effect. Therefore, the shoulder joint will undergo the action of extending/ flexing forces during the movement along longer/ shorter segments of the circle.

Position Singular Points. The PSPs at the elbow and shoulder joints coincide with the points of the movement trace where directions of the length changes of the proper muscles are inverted (Fig. 2C). Pairs of the PSPs, $\mathrm{L}_{\mathrm{e}}{ }^{(1,2)}$ (open triangles) and $\mathrm{L}_{\mathrm{s}}^{(1,2)}$ (closed triangles), correspond to extremal positions at the circle for the respective joint angles $\alpha$ and $\beta$; the extrema are defined by points where the corresponding coordinate traces $Z_{e}^{(1,2)}$ and $Z_{s}^{(1,2)}$ are touching the movement circle. Note that the elbow PSPs $\mathrm{L}_{\mathrm{e}}{ }^{(1,2)}$ are on the line passing via the axis of the shoulder joint $S$ and center of the movement trace O.

Singular Points and Force Synergy Sectors. Figure 2D describes the summarized location of FSPs and PSPs defined above (Figs. 2A-C) and illustrates the definition of the force synergy sectors (I-IV). The force correlations between different functional muscle groups belonging to different joints are most important for the treatment of the processes of central activation; therefore, it may be useful to define sectors at the movement trajectory with different combinations of the loadings on various muscle groups acting at different joints. During the movement in sectors I and II, muscles of the same modality, flexors $(f)$ or extensors $(e)$, are loaded at both joints; the choice between the combinations $f f_{s}$ and $e_{e} e_{s}$ (subscripts $e$ and $s$ denote elbow and shoulder) within the sectors I and II depends on the direction of the external force moment $\left(\mathrm{M}_{\mathrm{ccw}}\right.$ and $\left.\mathrm{M}_{\mathrm{cw}}\right)$. Combinations of the opposite modalities of the muscle loadings are observed in sectors III $\left(f_{e} e_{s}\right.$ and $\left.e f_{s}\right)$ and IV $\left(e f_{s}\right.$ and $\left.f_{e} e_{s}\right)$; these sectors are noticeably smaller, as compared with sectors I and II.

Force Synergy Sectors for the Movement Circles of Different Radiuses. The nonlinear character of the system under study creates obvious prerequisites for complex reordering in relative positions of singular points at the circular movement traces with changes in their radiuses. During such changes (Fig. 3A, B), steady angle positions are typical only of elbow joint PSPs (open triangles), whereas other singular points at both joints shift along specific smooth curves. 


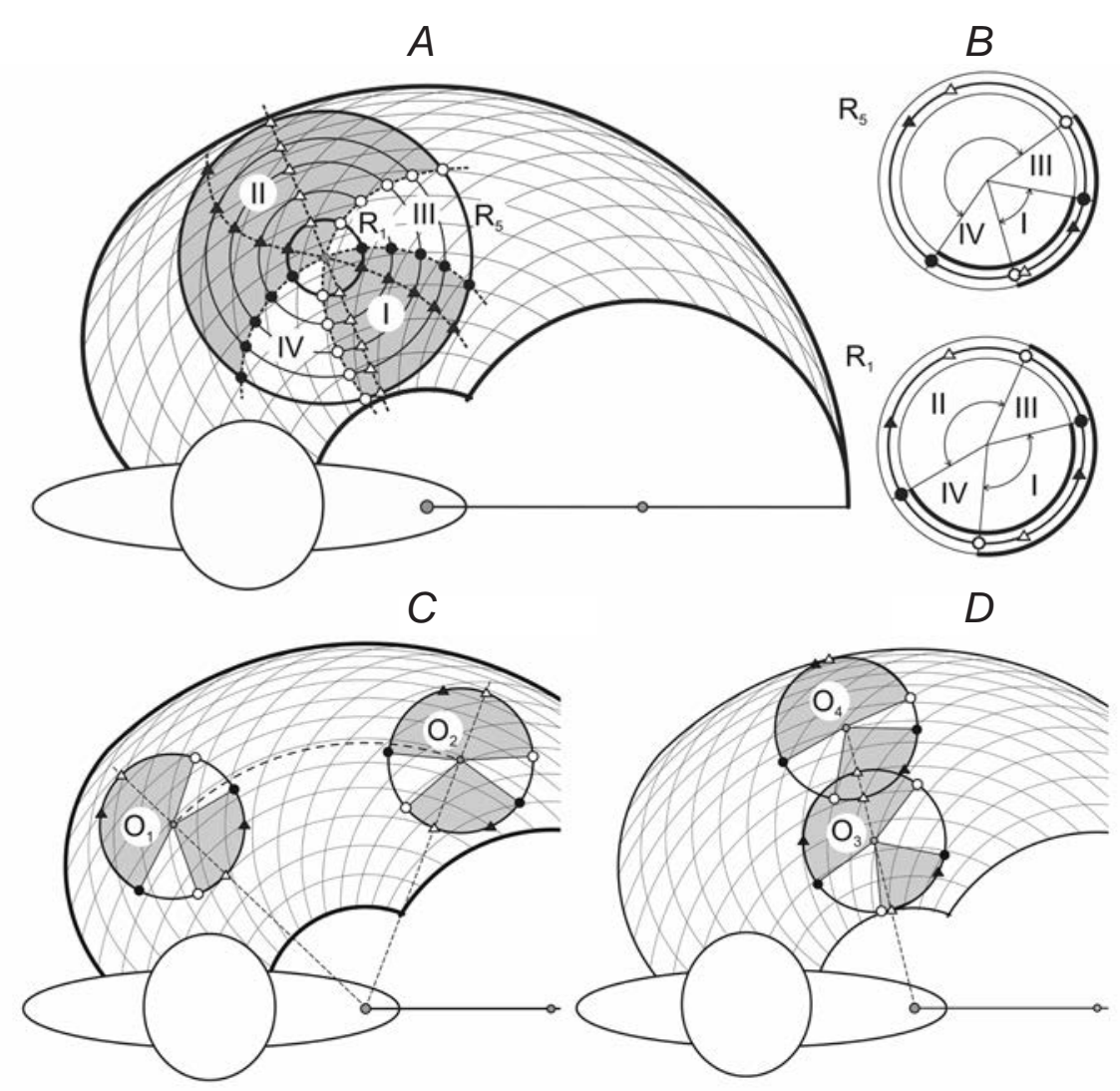

F i g. 3. Analysis of the differences between the patterns of singular points and force synergy sectors depending on the magnitude of the movements and on their location within the operational space. A) Singular points and force synergy sectors for the movement traces corresponding to concentric circles of different radiuses. B) Comparison of the force synergy sectors for circles of the maximal and minimal radiuses shown in $\mathrm{A}$. $\mathrm{C}$ and $\mathrm{D}$ ) Transitions of the movement circle center along a fixed "shoulder" coordinate line $\mathrm{O}_{1}-\mathrm{O}_{2}(\mathrm{C})$ and perpendicularly with respect to "shoulder" coordinate lines $\mathrm{O}_{3}-\mathrm{O}_{4}(\mathrm{D})$.

Р и с. 3. Аналіз розбіжностей патернів сингулярних точок та секторів силової синергії залежно від величини рухів та їх розташування в операційному просторі.

Changes in the positions of the FSPs are accompanied by reordering of the synergy sectors as well. When the radii are decreased, a certain smoothing of the differences between dimensions of the synergy sectors I and II is observed, while weights of the sectors III and IV remain almost invariable (Fig. 3B). It seems that these effects may be related to the varying degree of curvature of movement traces.

\section{Change in the Placement of Movement Traces.} Patterns of singular points in the identical circular movement traces remain unchanged for all traces placed at the same distance from the shoulder joint axis (Fig. 3C). In Cartesian coordinates, the set of singular points turns in the clockwise/counterclockwise direction in accordance with rightward/leftward turning of the line connecting the axis of the shoulder joint and the center of the movement circle. The relative weights of the force synergy sectors are also not changed in this case. On the contrary, shifts of the movement traces in the distal direction along the line passing via the axis of the shoulder joint (Fig. 3D) lead to increases in sectors I and II and corresponding decreases in sectors III and IV. It has been noted above that the distribution of the synergy sectors and their weights may depend on the degree of curvature of movement traces. In this case, the latter parameter is invariable; thus, it can be assumed that the observed changes depend on the curvature of the "shoulder", coordinate traces (concentric circles of different radii). On the other hand, these effects may also be related to turning of the "elbow" coordinate traces for more distal movement trajectories.

Ellipsoidal Movement Traces. Ellipsoids may be used for the description of more complex movement trajectories. Experimental setups in this case should be significantly more complicated, as compared with those used for studying circular movements [11]. These movements, however, may also be considered theoretically using the methods proposed above (Fig. 4). Determination of the "shoulder" FSPs would not differ from that described above for the circular traces. For the "elbow" FSPs, however, it is necessary to introduce two different curves, $Z_{e}{ }^{(\mathrm{ccw})}$ and $Z_{\mathrm{e}}{ }^{(\mathrm{cw})}$, describing opposite movement directions separately (Fig. 4A). These curves are constructed using (i) several defined points at the ends of the tangential segments $\mathrm{R}_{e}$ (five points for each loading direction are shown in Fig. 4A), and (ii) any kind of the nonlinear 


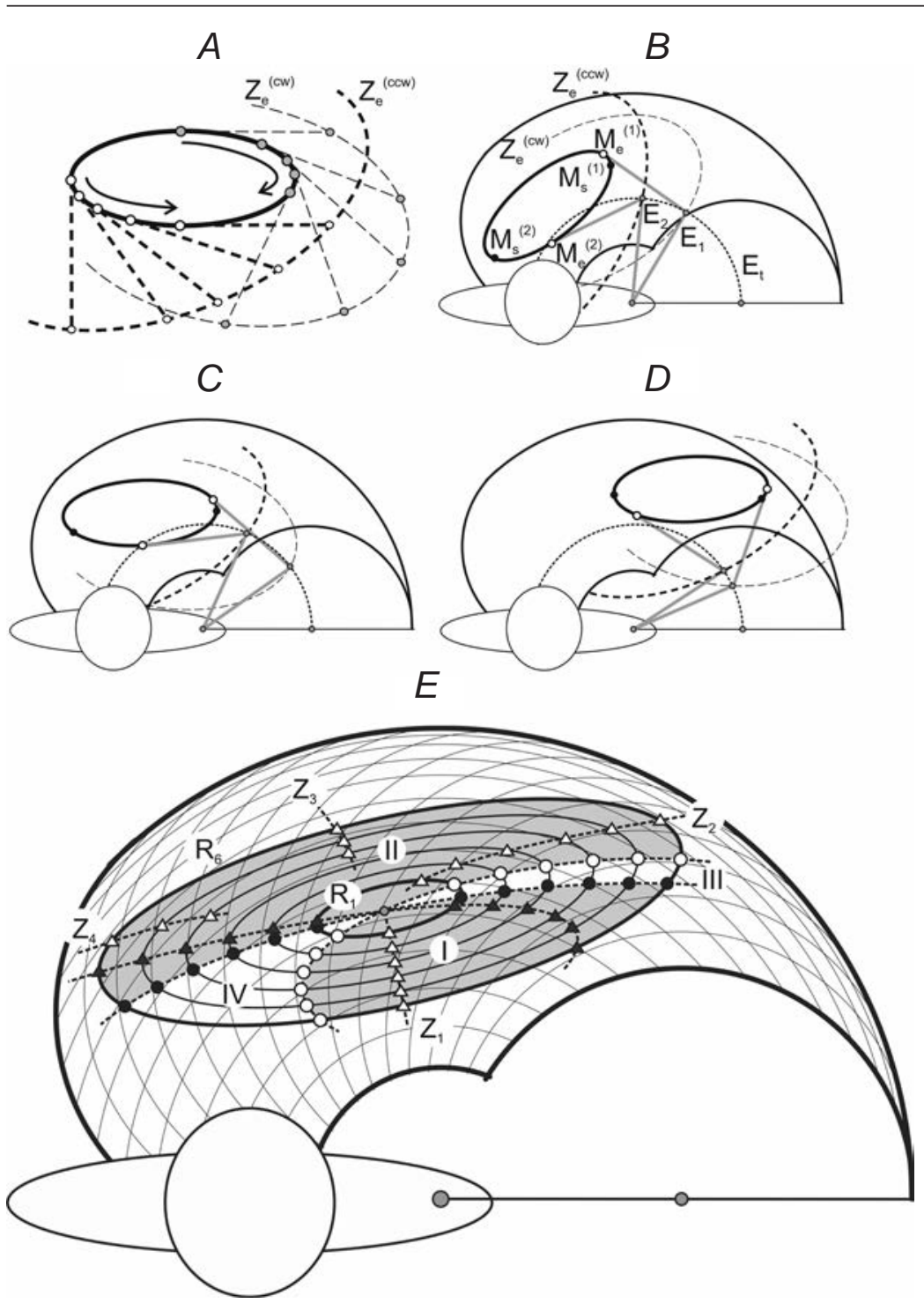

F i g. 4. Analysis of ellipsoidal trajectories of the movement. A) Definition of the force singular points (FSPs) for the elbow joint; auxiliary curves $Z_{\text {ccw }}$ and $\mathrm{Z}_{\mathrm{cw}}$ coincide with virtual trajectories of the elbow joint positions with a zero moment. B, C, and D) Definition of the FSPs and proper elbow joint positions for different placements of the ellipsoids within the operational space. E) Location of the singular points and force synergy sectors at the ellipsoidal movement traces of various dimensions; note the complex pattern of the "elbow" PSPs; in addition to the PSPs located along the lines $Z_{1}$ and $Z_{2}$, in a part of the larger ellipses $\left(\mathrm{R}_{4}-\mathrm{R}_{6}\right)$, pairs of additional PSPs $\left(\mathrm{Z}_{3}\right.$ and $\mathrm{Z}_{4}$ branches) appear.

Р и с. 4. Аналіз еліпсоїдних траєкторій руху.

smooth approximation procedure. Further positioning of the ellipsoidal trace within the operational space should be further considered with $Z_{e}{ }^{(\mathrm{ccw})}$ and $Z_{e}{ }^{(\mathrm{cw})}$ curves fixed to the movement trace (Fig. 4B-D). Transections of these auxiliary curves with the elbow trace $E_{t}$ define the elbow joint positions $\left(E_{1}, E_{2}\right)$, which correspond to the required FSPs $\mathrm{M}_{\mathrm{e}}^{(1,2)}$.

Ellipsoidal Movement Traces of Different Sizes. Using the methods described above, we can define singular points for a system of ellipsoidal movement traces of different sizes (Fig. 4E). The distributions of the FSPs and of the force synergy sectors is largely similar to those of the concentric circular traces presented in Fig. 6, although some elongation of the traces leads to the respective shifts of the FSPs along larger axes of the ellipses, thus changing the force synergy sectors. It may be emphasized that sectors III and IV decrease in this case, as compared with those in the circular traces (Fig. 3A). Elongation of the movement traces also evokes an interesting phenomenon, namely the appearance of two additional elbow PSPs (lines $Z_{3}$ and $Z_{4}$ ) at larger-size traces $\left(\mathrm{R}_{4}-\mathrm{R}_{6}\right)$ in Fig. 4E. Most likely, this can be related to differences in the curvature degree of different traces and/or to the dependence on positioning of the ellipses within the operational space.

Singular Points in the Linear Movement Traces. Linear (or quasi-linear) traces may be considered important elements of many real movements. A method allowing one to define the "elbow" FSPs for the linear movements is considered below. Similarly to the circular and ellipsoidal movements, 


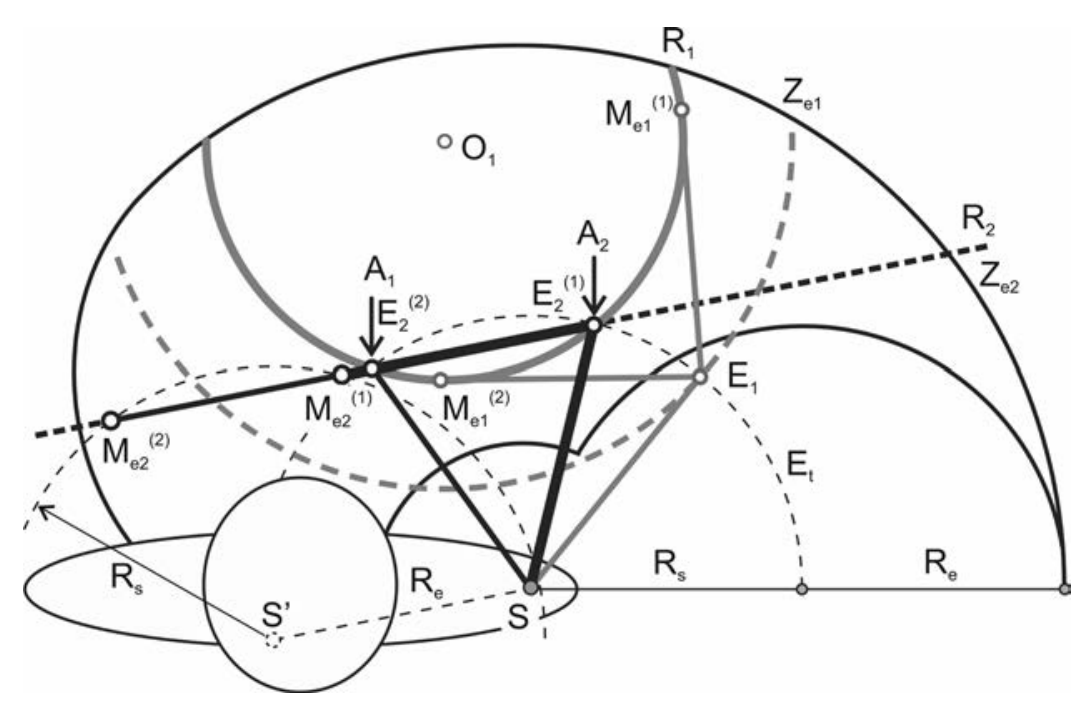

F i g. 5. Elbow force singular points (FSPs) at the linear movement traces. The linear trace $R_{2}$, passing via points $A_{1}$ and $A_{2}$, corresponds to a limit passage of the circle $R_{1}$ passing via the same points during an endless radius increase. The virtual trajectory of the elbow joint positions with a zero moment for the $R_{1}$ circle is presented by arc $Z_{\mathrm{el}}$, whereas such a trajectory for the line $\mathrm{R}_{2}\left(\mathrm{Z}_{\mathrm{e} 2}\right)$ coincides with the movement trace itself. In this case, it is possible to define two joint positions, $\mathrm{E}_{2}{ }^{(1,2)}$, and corresponding FSPs, $\mathrm{M}_{\mathrm{e} 2}{ }^{(1,2)}$, for the movement line $R_{2}$. An important condition for the existence of the "elbow" FSPs is the necessity for the linear movement trace to intersect (or, at least, to touch) the trajectory of possible movements of the elbow joint $\mathrm{E}_{\mathrm{t}}$; the FSPs defined in this way cannot exit out of the limits of the operational space.

Р и с. 5. Силові сингулярні точки для передпліччя на траєкторіях лінійних рухів. the loadings are in this case also directed along the movement trajectory (Fig. 5). The main problem for linear movements is related to the definition of the "elbow" FSPs. For this purpose, we shall analyze two traces, the circular $\mathrm{R}_{1}$ and the linear $\mathrm{R}_{2}$, going through two points, $A_{1}$ and $A_{2}$. In accordance with the method described earlier, for circle $\mathrm{R}_{1}$ we can define both the position of the elbow joint $E_{1}$ (as the point of crossing of the auxiliary curve $\mathrm{Z}_{\mathrm{e} 1}$ with the elbow trace $\mathrm{E}_{\mathrm{t}}$ ) and the related FSPs $M_{e 1}{ }^{(1,2)}$. On the other hand, the linear trace $R_{2}$ may be presented as a result of the endless increase in the radius of circle $R_{1}$ under conditions of its going through points $A_{1}$ and $A_{2}$. In this case, the auxiliary curve $Z_{\mathrm{e} 2}$ will coincide with the movement trace itself, i.e., with the $\mathrm{R}_{2}$ line. Therefore, since $A_{1}$ and $A_{2}$ are points of crossing of the curves $Z_{e 2}$ and $E_{t}$, they also coincide with the elbow positions $E_{2}^{(1,2)}$ where the forces are going through the joint axis, and the "forearm" is oriented along line $\mathrm{R}_{2}$. The additional condition for the appearance of the FSPs in the linear movement trace is its crossing of (or, at least, touching to) the elbow trace $\mathrm{E}_{\mathrm{t}}$. On the other hand, there are positions where possible FSPs could exit out of the operational space.

Synergy Areas for Sets of Parallel Linear Movement Traces. The above-described approach for finding the "elbow" FSPs in the linear movement traces may be used to define the synergy areas for sets of parallel linear movement traces having various slopes (Fig. 6). In the movement traces going orthogonally with respect to the frontal plane (Fig. $6 \mathrm{~A})$, the "elbow" FSPs are defined using the auxiliary curve $Z_{e}$. This curve coincides with the elbow trace $E_{t}$ shifted vertically for the distance $R_{e}$ along the movement trace of a zero loading (line $\mathrm{z}$ in Fig. 6A). The FSPs can be defined as points of crossing of curve $Z_{e}$ with the movement traces located rightward from line $z$. The "forearm" locations at these FSPs coincide with the movement traces; the proper positions of the shoulder segment are shown by dotted lines going toward small circles at curve $\mathrm{E}_{\mathrm{t}}$. Note that the FSPs are absent on the left with respect to line $z$, because points of crossing of the auxiliary curve $Z_{e}$ with the movement traces do not obey to a natural condition of positivity for the elbow joint angles (the forearm cannot be placed along these traces without destroying the joint).

The $\operatorname{arc} \mathrm{Z}_{\mathrm{e}}$ and line $\mathrm{z}$ constitute natural boundaries confining the synergy area III (marked in gray in Fig. 6A), where muscles of different modality acting on the elbow and shoulder joints are loaded. In two other areas of synergy (I and II), muscle groups of the same modality are loaded. Similarly to the circular movements, the antagonistic muscles are loaded with a change in the direction of the external loading. The synergy areas may also be defined in a similar way for other directions of the movement traces (Fig. 6B - D). In these cases, the corresponding rotation of the same synergy areas (I - III) is observed in accordance with turning of line $\mathrm{z}$. For positions of the movement traces shown in panels B and D of Fig. 6, it is possible to observe the disappearance of both line $\mathrm{z}$ and area II due to natural limitations of the operational space. In accordance with the general definition, the $\mathrm{z}$ lines 
A
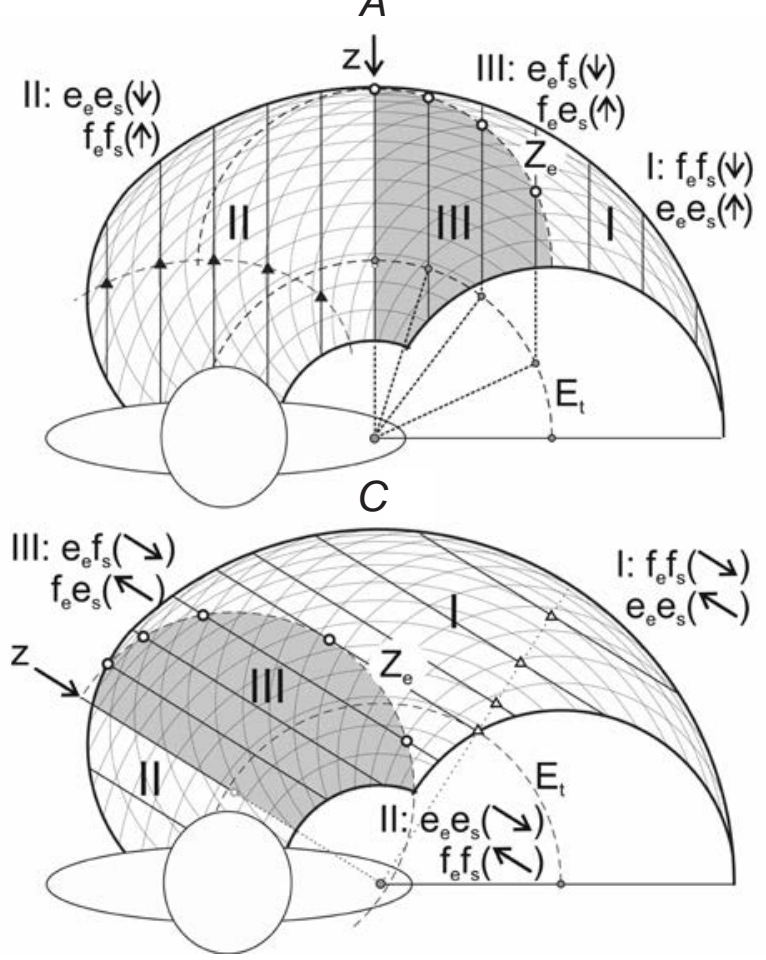

$B$
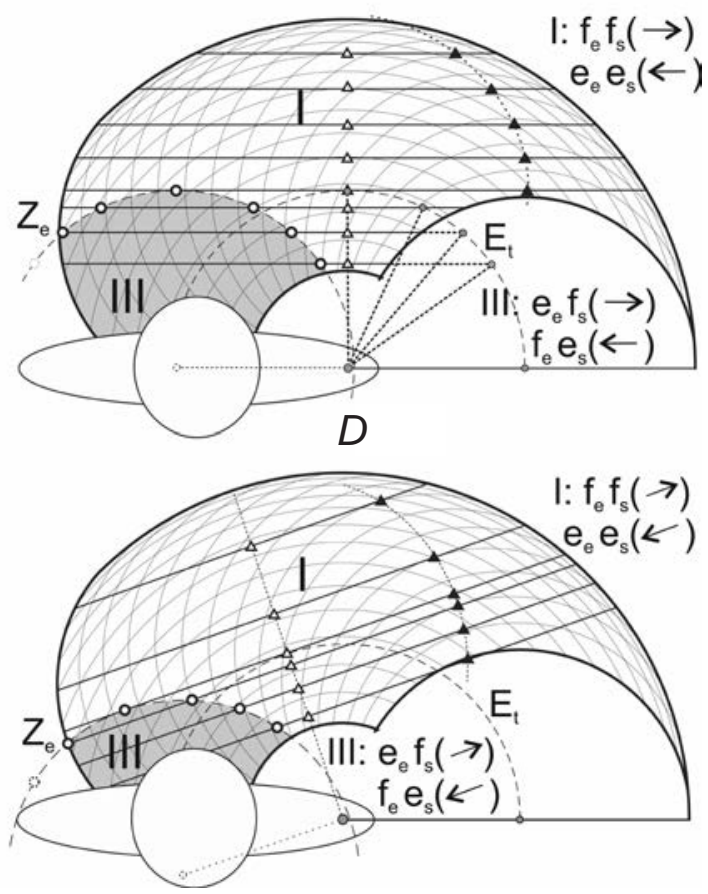

F i g. 6. Force and position singular points (FSPs and PSPs) and force synergy areas defined for sets of the parallel linear movement traces of different directions. A-D) Areas III (marked in grey) correspond to the opposing patterns of loading, when the elbow flexors are loaded together with the shoulder extensors, and vice versa; areas I and II correspond to the coinciding patterns of loading for the muscles belonging to different joints. Designations are the same as in Fig. 5; the load directions are shown by arrows in brackets. The lines marked by arrow $\mathrm{z}$ in panels $\mathrm{A}$ and $\mathrm{D}$ designate traces of the zero moment at the shoulder joint.

Р и с. 6. Силові та позиційні сингулярні точки та зони силових синергій, визначені для серій паралельних траєкторій лінійних рухів різного напрямку.

in all sets of the parallel movement traces divide the entire operational space in accordance with the sign of the force moment at the shoulder joint. The absence of the line $\mathrm{z}$ at a given movement direction signifies that the force moment at the shoulder joint does not change its sign within the entire operational space.

In addition to the FSPs and the respective synergy areas, all panels in Fig. 6 include lines of distribution of the PSPs, where the directions of the muscle length change in the corresponding joints are reversed.

\section{DISCUSSION}

Force and Position Synergies. Our study is devoted to a theoretical analysis of various types of planar movements produced under different combinations of directions of both the external force moment and the movement itself. It has been shown earlier that central commands to the muscles in two-joint movements depend predominantly on the relative positions of the FSPs where the force moments change their directions [11]. At the same time, the commands are also dependent on the PSPs connected with the extremal points at the joint angle traces. In this study, the positions of singular points in the movement traces were defined graphically. This approach allows the researcher to analyze not only circular traces, but separate elements of more complex trajectories as well.

Formally, the force synergies may be classified in accordance with the functional modality of the muscles belonging to different joints, which are loaded simultaneously. The coinciding synergy corresponds to simultaneous loading of muscles of the same modality (flexors-flexors; extensors-extensors); while the opposing synergy belongs to combinations of muscles 
of different modality (flexors-extensors; extensorsflexors). Muscle combinations within both types of the synergy effects depend on the loading direction. It is interesting that, in all the considered types of movement trajectories, both closed (circular and ellipsoidal) and open (linear) ones, the prevalence of the coinciding synergies is manifested. In the circular traces, the weight of the coinciding synergy sectors (I, II) is greater, as compared with that of the opposing synergy ones (III, IV). In ellipsoidal traces, these differences seem to be expressed even more clearly (compare Figs. 3A and 4E). In the general case of the parallel movement traces going under different angles to the subject's frontal plane (Fig. 6), the operational space is usually divided into three areas, two of which are connected with the coinciding synergy (I, II), while the third one is related to the opposing synergy (III). Similarly, the weight of the coinciding synergy areas seems to be relatively greater as compared to that of the opposing synergy.

The force synergy patterns are changed for identical circular movement traces going at different distances from the shoulder axis (Fig. 3D). At the same time, both relative distribution of singular points and weights of the synergy sectors remain unchanged for the same distances from the shoulder axis, and the pattern of all synergy points is simply rotated in the course of such a transition (Fig. 3C). At present, preliminary analysis of the FSPs (Figs. 3 and 4) allows us to conclude that the observed variabilities of the force synergy patterns at various parts of the operational space are likely related to the differences in the curvature indices of both movement trajectories and traces of the curvilinear coordinate system.

The position synergy is defined by the distribution of PSPs along the movement trajectories, and its influence is directly related to muscle hysteresis (for review, see [13]). The effects of the position synergy are often smoothed when PSPs are placed close to the nearest FSPs, although the movement-dependent differences in the EMG intensities may be also rather significant, especially for distal muscles [11].

Activation Synergy. Despite strong experimental support for the assumption of existence of connections between force and activation synergies in real circular movements [11], it has been demonstrated in the cited study that EMG activities of the elbow and shoulder muscles may be rather noticeable out of the zones of their direct loading. This phenomenon may be related to a more complicated arrangement of the joints, as compared with that in a simple pivotal model.
An exhausting analysis of the complex geometry of the rotation movements in the shoulder joint can be found in [14]. The elbow joint biomechanics is highly intricate as well; recently, it has been considered as an assemblage of three interactive joints [15]. It seems that such complex mechanical systems as the elbow and shoulder joints can provoke indeterminacy in the force moments acting around these joints.

It is quite clear that, with change in the movement pattern, muscle activities are rearranged in correspondence to new movement tasks. At the same time, it should be noted that classification of the muscles as belonging exclusively to the elbow or shoulder joints is noticeably oversimplified; sites of the force applications can be fixed only for the monoarticular muscles, while the procedure of their identification for the biarticular muscles is significantly more complex [16].

The set of efferent activities controlling two-joint movements is often localized within separate time or space zones within which programs of co-contraction can predominate. The movement phases are primarily accompanied by co-contractions of the antagonistic muscles within the areas adjacent to the zones of their direct loading. The co-contraction patterns can distinctly reduce both the after-effects of the ongoing residual movements at the apexes of movement and the uncertainty effects related to muscle hysteresis $[13,17]$. Behavioral studies of postural tasks have demonstrated that subjects use muscle co-contraction as a strategy of stabilization of the limb joints in the presence of external loadings [18]. Humans are also able to modulate independently the relative balance of co-contraction and limb stiffness in different spatial directions [19] and at different joints [20]. At the same time, co-contraction of the antagonistic muscles should increase the energy costs of the real movements.

Force Feedback Control Hypothesis. The close resemblance of the force and activation synergies allows us to propose the force feedback control hypothesis, which introduces a hypothetical mechanism via which the CNS can regulate descending motor commands in multi-joint movements. This mechanism can be based on using feedback signals with information on the presence or absence of loading of the antagonistic muscles acting on joints participating in a given movement. During the movement, any crossings of the FSPs belonging to a given joint would evoke "inversion" of the corresponding feedback signals, thus informing the motor control system on the necessity to redirect descending activity between the groups of antagonistic muscles of a given joint. As a 
result, muscles that were active earlier become silent, while their antagonists are activated. At any moment, predominant activation is directed toward the muscles loaded by the force moment acting at the proper joint. The Golgi tendon organs seem to be the best candidates for providing this force afferent signals, although the involvement of other proprioceptor types in this process cannot be ruled out as well. Voluntary control can also participate in this case for both co-contraction of the antagonistic muscles and the desired shaping of the movement trajectories. The co-contraction of the antagonistic muscles is better seen within the trace areas located near the correspondent FSPs [11]. The force feedback control hypothesis can probably explain the decrease in the number of controlled variables during multi-joint movements due to the possibility for the CNS to use simultaneously the complex of proprioceptive information coming from all joints involved in a given movement program. Moreover, such "force information matrix" might be created without any additional expense for the CNS on the assessment of the real position and forces at the joints involved in the movement. In this case, it is likely that this automatically obtained information concerning the force synergy is simply "transformed" into a preliminary pattern of the activation synergy, which is naturally needed in some voluntary modifications, in order to obtain the desired parameters of the movements.

Acknowledgment. This work was supported by the grant 0024/RSA2/2013/52 from the Rozwój Sportu Akademickiego, Poland.

This study is devoted to theoretical analysis of the processes of motor control; it was not directly related to experiments on animals or tests on humans. Therefore, it does not require the confirmation of compliance with the existing international ethical standards for experimental studies.

The author, A. I. Kostyukov, confirms the absence of any conflict related to the commercial or financial problems and to the relations with organizations or persons, which could in any way be associated with the investigation.
O. I. Костюков ${ }^{1,2}$

\section{ТЕОРЕТИЧНИЙ АНАЛІЗ СИЛОВИХ ТА ПОЗИЦІЙНИХ СИНЕРГІЙ У ДВОСУГЛОБОВИХ РУХАХ}

\author{
${ }^{1}$ Університет фізичного виховання та спорту, Гданськ \\ (Польща). \\ ${ }^{2}$ Інститут фізіології ім. О. О. Богомольця НАН України, \\ Київ (Україна).
}

P е 3 ю м е

Пропонується теоретичний підхід для визначення силових та позиційних сингулярних точок (ССТ та ПСТ відповідно) при циркулярних, еліпсоїдних та лінійних двосуглобових рухах у площині, які реалізуються в разі наявності постійних навантажень, орієнтованих вздовж траєкторій рухів. ССТ співпадають із точками зміни напрямку моментів сили, які діють на суглоби, а ПСТ відповідають розташуванню екстремумів на траєкторіях суглобових кутів. Силова синергія, що визначається розташуванням ССТ, інтенсивно впливає на синергію активації; остання в основному описується кореляціями між активністю м'язів, залучених у реалізацію руху. Позиційна синергія, що визначається розташуванням ПСТ, відповідальна за пов'язану з гістерезісом модуляцію активаційної синергії. Пропонуються геометричні процедури для визначення положень ССТ та ПСТ на траєкторіях різних рухів; це може допомогти формуванню загального опису силових та позиційних синергій для різних рухів. Силові синергії в кругових рухах перекривають чотири сектори 3 різними комбінаціями м'язів-флексорів та екстензорів, що діють на різні суглоби. Аналізовано варіативність ефектів синергії щодо величини та розташування кругових траєкторій; патерни синергії розглядаються також для еліпсоїдних та лінійних траєкторій рухів. Запропоновано гіпотезу контролю сили на базі зворотного зв'язку; вона дозволяє пояснити зменшення кількості контрольованих змінних величин у перебігу реальних багатосуглобових рухів.

\section{REFERENCES}

1. M. Santello and J. F. Soechting, "Force synergies for multifingered grasping," Exp. Brain Res., 133, 457-467 (2000).

2. P. H. Thakur, A. J. Bastian, and S. S. Hsiao, "Multidigit movement synergies of the human hand in an unconstrained haptic exploration task," J. Neurosci., 28, 1271-1281 (2008).

3. I. V. Grinyagin, E. V. Biryukova, and M. A. Maier, "Kinematic and dynamic synergies of human precision-grip movements," J. Neurophysiol., 94, 2284-2294 (2005).

4. J. K. Shim, H. Olafsdottir, V. M. Zatsiorsky, and M. L. Latash, "The emergence and disappearance of multi-digit synergies during force-production tasks," Exp. Brain Res., 164, 260-270 (2005). 
5. A. W. Hooke, S. Karol, J. Park, et al., "Handwriting: threedimensional kinetic synergies in circle drawing movements," Motor Control, 16, 329-352 (2012).

6. C. Castellini and P. van der Smagt, "Evidence of muscle synergies during human grasping," Biol. Cybern., 107, 233 245 (2013).

7. M. L. Latash, J. P. Scholz, and G. Schoner, "Toward a new theory of motor synergies," Motor Control, 11, 276-308 (2007).

8. B. Poston, A. Danna-Dos Santos, M. Jesunathadas, et al., "Force-independent distribution of correlated neural inputs to hand muscles during three-digit grasping," J. Neurophysiol., 104, 1141-1154 (2010).

9. A. V. Lehedza, A. V. Gorkovenko, I. V. Vereshchaka, et al., "Comparative analysis of electromyographic muscle activity of the human hand during cyclic turns of isometric effort vector of wrist in opposite directions," Fiziol. Zh., 61, No. 2, 3-14 (2015).

10. T. Tomiak, A. V. Gorkovenko, A. N. Tal'nov, et al., "The averaged EMGs recorded from the arm muscles during bimanual "rowing" movements," Front. Physiol., 6, No. 349, doi: 10.3389/fphys.2015.00349 (2015).

11. T. Tomiak, T. I. Abramovych, A. V. Gorkovenko, et al., "The movement- and load-dependent differences in the EMG patterns of the human arm muscles during two-joint movements (a preliminary study)," Front. Physiol., 7, No. 218, doi: 10.3389/fphys.2016.00218 (2016).
12. P. D. Neilson, M. D. Neilson, and R. T. Bye, "A Riemannian geometry theory of human movement: The geodesic synergy hypothesis," Human. Mov. Sci., 44, 42-72 (2015).

13. A. I. Kostyukov, "Muscle hysteresis and movement control: a theoretical study," Neuroscience, 83, 303-320 (1998).

14. A. M. Hill, A. M. J. Bull, A. L. Wallace, et al., "Qualitative and quantitative descriptions of glenohumeral motion," Gait Posture, 27, No. 2, 177-188 (2008).

15. C. D. Bryce and A. D. Armstrong, "Anatomy and biomechanics of the elbow," Orthop. Clin. North Am., 39, No. 2, 141-154 (2008).

16. B. M. Van Bolhuis, C. C. Gielen, and G. J. van Ingen Schenau, "Activation patterns of mono- and bi-articular arm muscles as a function of force and movement direction of the wrist in humans," J. Physiol., 508, 313-324 (1998).

17. A. V. Gorkovenko, S. Sawczyn, N. V. Bulgakova, et al., "Muscle agonist-antagonist interactions in an experimental joint model," Exp. Brain Res., 222, 399-414 (2012).

18. T. E. Milner and C. Cloutier, "Damping of the wrist joint during voluntary movement," Exp. Brain Res., 122, 309-317 (1998).

19. E. Burde, R. Osu, D. W. Franklin, et al., "The central nervous system stabilizes unstable dynamics by learning optimal impedance," Nature, 414, 446-449 (2001).

20. P. L. Gribble and D. J. Ostry, "Independent coactivation of shoulder and elbow muscles," Exp. Brain Res., 123, 335-360 (1998). 